\title{
Structural organization of personal resources of coping behavior of students with different levels of self-organization of activity
}

\author{
Elena Suroedova, ${ }^{1, *}$, Galina Uvarova $^{2}$, Nogala Shevkieva ${ }^{2}$ \\ ${ }^{1}$ Don State Technical University, pl. Gagarina, 1, Rostov-on-Don, 344003, Russian Federation \\ ${ }^{2}$ Kalmyk State University named after B. B. Gorodovikova, st. Pushkin, 11, Elista, 358011, Russian \\ Federation
}

\begin{abstract}
The development of personal resources of coping behavior of students is possible under the condition of structuring personal time, tactical planning and strategic goal-setting, i.e. self-organization of activities. This article examines the features of the structure of personal resources of coping behavior of students with an average and high level of the general indicator of self-organization of activity. The study involved 67 students aged 19 to 21 years. Methods were used: survey; statistical methods (descriptive statistics, Spearman rank correlation coefficient, structural - psychological analysis according to generalized indicators of the index of organization, integrativity and differentiation of the structure, the express- $\mathrm{x} 2$ method for comparing matrices and structuralograms for their «homogeneity b-heterogeneity» (A.V. Karpov). The study established significant differences in the structural organization of such personal resources of coping behavior as indicators of optimism, self-efficacy, selfcontrol, components of reflection, parameters that ensure the process of structuring personal time, tactical planning, strategic goal-setting among students with a high and average level of the general indicator of selforganization of activity. Research prospects are aimed at studying the structure of personal resources of coping behavior of students with a low level of the general indicator of self-organization of activity.
\end{abstract}

\section{Introduction}

Education at a university is the most important stage in the socialization and personal development of young people, and also becomes the first step in the formation of social maturity and such features as responsibility, humanity and humanism, professional selfdetermination and self-development, focus on productivity and efficiency, development of moral and ethical and moral qualities. The educational environment contributes not only to the formation of professional competence and self-awareness of young people, but also develops personal qualities necessary for a modern person, such as self-organization, selfgovernment, reflection, optimism, tolerance, self-efficacy, resilience [1-3]. Studies by Russian scientists show that these properties are personal resources in various life

\footnotetext{
*Corresponding author: suroedova@mail.ru
} 
situations, including educational and work activities. T. V.Eksakusto, I. A.Kibal'chenko defines personal resources as a complexly organized education, consisting of various structural components of the personality, which determine its success in educational, professional activities and in personal life [1].

The ability to self-organize and self-regulation of their behavior and activities today is required not only for adults, but for children and youth. Recent events related to the COVID-19 pandemic and the transition to distance learning have shown that modern schoolchildren and students must possess the skills of time management, self-organization techniques, goal-setting and self-motivation techniques, conscious focus in educational activities, manifestation of volitional efforts and self-control. The results of the research by S. Kostromina showed that educational activity actualizes those characteristics that to the greatest extent ensure the assimilation of educational material and the achievement of educational goals at the personal level, and the most significant result of mastering is the student's ability to learn independently, that is, to purposeful, internally motivated structured personality and adjusted by him in accordance with the process and result of educational activities. Motivation for achievement is closely related to the self-organization of educational activity, which allows you to control your cognitive, emotional and personal resources and is a key element of the system of self-regulation of educational activity [4]. N.F. also speaks about the importance of the motivational aspect in self-organization of learning. Efremov [5]. The success of training and self-management of activities largely correlates with personal aspects and competencies: communicative competence and the ability to convey meaning $[6,7]$, value-semantic aspects $[8,9]$, emotional qualities of the subject [10-11].

Self-organization in Russian psychology is usually understood as a spontaneous process of self-adjustment and ordering of life through the optimization of social ties, accompanied by the emergence of new structures or the transformation of existing ones at the time of their extreme instability [12]. In some studies, self-organization is seen as synonymous with self-regulation. Yu. A. Zubok points out that self-regulation of youth life is a complex and multi-layered process that is not limited to simple determination of factors [13]. V. I. Morosanova consider self-organization as a set of behavioral traits such as responsibility, self-control and foresight. Studying the features of self-organization of the student's personality, Pakhmutova M., Bakhtina S., Rybakov A. and others believe that it (selforganization) is a manifestation of the integrity of the personality and is associated with the formation of the subjectivity of the future professional, where the research activity of students can act as a condition for the formation of his subjectivity. Researchers note that self-organization is an independent step-by-step construction by a person of the structure of his traits, motives, ideals and has two aspects: the construction of an «self-image» or selfesteem is an internal aspect, and the organization of his activity or its success is an external aspect [14].

V.V. Bondaletov, summarizing various psychological and sociological approaches to the phenomenon of self-organization, concludes that the desire for self-organization is a rational choice of the subject. In the first case, rationality is characterized by the clarity and unambiguity of the understanding by the interacting subjects of their benefits (needs, interests, aspirations), in the second - the conscious and free acceptance of social (normative and value) standards. That is, the choice of self-organization as a method of action is made on the basis of an assessment of their effectiveness in achieving a goal or an idea of social duty. It is through the rationality of goals, the expediency of the chosen means, that the desire for self-organization arises. At the same time, the author notes, it is not at all important - this desire appears in the subject under the influence of external or internal factors, since in the first and second cases it is the result of his conscious and voluntary choice [15]. 
In world science, the concept of self-organization is most often used in the natural sciences, sociology, pedagogy and philosophy. Thus, Karl Friston's research raises the question of the self-organization of internal processes in accordance with perception, and the action connects the state of the brain with the outside world [16]. In a study by José Nederhand, Erik-Hans Klijn, Martijn van der Steen, Mark van Twist, the question of the processes of self-organization of society and the search for new innovative ways of public administration was raised [17]. Studying the vocal ability of children, Clément MoulinFrier, Sao M. Nguyen and Pierre-Yves Oudeyer established mechanisms for the transition from vocal self-exploration with little influence of the speech environment to a later stage, when vocal exploration becomes influenced by peer vocalization. The authors proved the self-organization of the sequence of vocal activity formation [18]. In the works of Rick Dale, Riccardo Fusaroli, Nicholas D. Duran, Daniel C. Richardson the self-organization of communicative and interactive interaction of people, the stages and psychological patterns, and the mechanisms of self-development (or self-development) of the communication process are considered [19].

\section{Materials and Methods}

The study involved 67 students aged 19 to 21 years $(M=20.4, S D=0.81(67.2 \%$ men). The sample consisted of bachelor students enrolled in the second-fourth courses in the areas of training 15.03.02 Technological machines and equipment, 19.03.02 Food from vegetable raw materials, 19.03.03 Food of animal origin, faculty «Agroindustrial», Don State Technical University Methods were used: survey - «Questionnaire of selforganization of activities» (E. Yu. Mandrikova), «Test for optimism» (Ch. Scheyer, M. Carver, adaptation by O. A. Sychev) [20], the method «Scale of general self-efficacy» (R. Schwarzer, M. Erusalema, adaptation of V. Romek), methodology «Brief scale of selfcontrol» (J. Tangney, R. Baumeister, A. L. Boone, adaptation of T. O. Gordeeva, E. N. Osina, D. D. Suchkova, T. Yu. Ivanova, O. A. Sycheva, V. V. Bobrova), «Methods for the diagnosis of reflexivity» (A.V. Karpov, V. V. Ponomareva), New questionnaire of tolerance to uncertainty and (NTN questionnaire modified by T.V. Kornilova); statistical methods (descriptive statistics, Spearman rank correlation coefficient, structural - psychological analysis according to generalized indicators of the index of organization, integrativity and differentiation of the structure (A.V. Karpov), the method of express- $\mathrm{x}^{2}$ for comparing matrices and structuregrams on their «homogeneity-heterogeneity» (A. V. Karpov).

The purpose of the study was to study the features of the structural organization of personal resources of coping behavior of students with different levels of the general indicator of self-organization of activity.

The assumption was tested that there are significant differences in the structural organization of such personal resources of coping behavior as indicators of optimism, selfefficacy, self-control, reflection components, parameters that provide the process of structuring personal time, tactical planning, strategic goal-setting among students with high and medium levels. general indicator of self-organization of activity.

\section{Results}

The entire sample $(\mathrm{N}=67)$ was differentiated into two subgroups depending on the level of the general indicator of self-organization of activity: an average level $(\mathrm{N}=33)$ and a high level $(\mathrm{N}=34)$. Then the procedure of multivariate correlation analysis of the measured indicators was carried out. The intercorrelation matrices of the studied indicators were studied and, on their basis, structuralograms of significantly correlated measured indicators 
were created, the structural organization indices (coherence index, divergence index and structure organization index) were calculated.

Figure 1 shows the structogram of coping behavior personal resources for a subgroup of students with an average level of the general indicator of self-organization of activity.

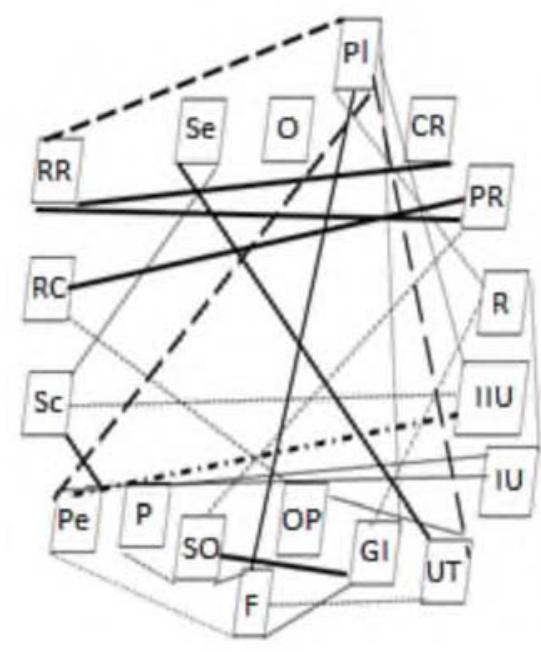

Fig. 1. Structogram of personal resources of coping behavior in students with an average level of the general indicator of self-organization of activity

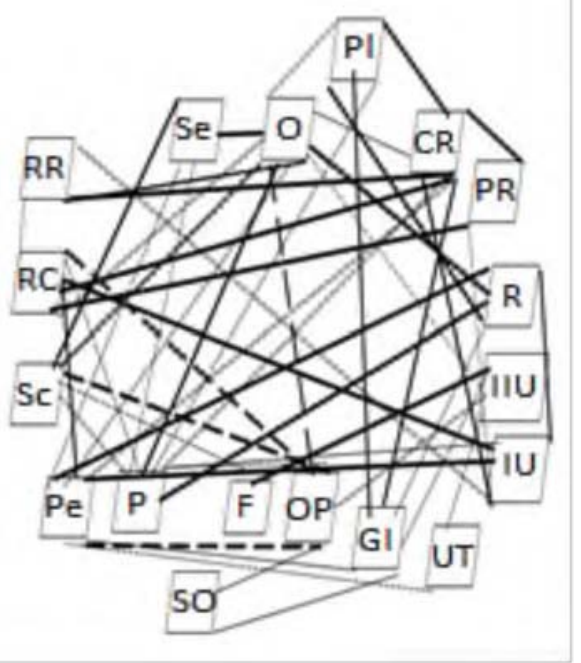

Fig. 2. Structogram of personal resources of coping behavior in students with a high level of the general indicator of selforganization of activity

Notes: O - optimism; Se - self-efficacy; Sc - self-control; RR - retrospective reflection; $\mathrm{CR}$ - situational reflection, $\mathrm{PR}$ - perspective reflection; $\mathrm{RC}$ - reflection of communication; $\mathrm{R}$ - reflexivity; Pl - planarity; $\mathrm{P}$ - purposefulness; $\mathrm{Pe}$ persistence, $\mathrm{F}$ - fixation, $\mathrm{SO}$ - self-organization, OP - orientation to the present, GI general indicator of self-organization of activity; UT - uncertainty tolerance; IU intolerance to uncertainty; IIU - interpersonal intolerance to uncertainty.

Positive correlation $(\mathrm{p} \leq 0,01)$,

Positive correlation $(\mathrm{p} \leq 0,05)$,

Negative correlation $(\mathrm{p} \leq 0,01)$,

Negative correlation $(\mathrm{p} \leq 0,05)$.

As can be seen from Figure 1, in the subgroup of students with an average level of the general indicator of self-organization of activity, the indicator of optimism is not associated with the personal resources of coping behavior. As Figure 2 shows, in the subgroup of students with a high level of the general indicator of self-organization of activity, the indicator of optimism is positively correlated with many personal resources of coping behavior.

It should be noted that in the subgroup of students with an average level of the general indicator of self-organization of activity between the indicators of personal resources of coping behavior, the number of connections was found - $27(\mathrm{p} \leq 0,05$ and $p \leq 0,01)$, in the subgroup of students with a high level of the general indicator of self-organization of activity - the number of bonds $-53(\mathrm{p} \leq 0,05$ and $\mathrm{p} \leq 0,01)$.

On the basis of the presented data, the values of the indices of the structural organization of the measured indicators were calculated in a subgroup of students with an 
average level and a high level of the general indicator of self-organization of activity. The results are shown in Table 1.

Table 1. The values of the indices of the structural organization of personal resources of coping behavior in students with different levels of the general indicator of self-organization of activity

\begin{tabular}{|c|c|c|}
\hline \multirow[t]{2}{*}{ Indexes } & \multicolumn{2}{|c|}{$\begin{array}{l}\text { The level of the general indicator of self-organization } \\
\text { of activity }\end{array}$} \\
\hline & Middle level & High level \\
\hline Coherence structure & 37 & 112 \\
\hline Divergence of structure & 30 & 20 \\
\hline General organization index & 7 & 92 \\
\hline
\end{tabular}

The analysis showed that the degree of coherence (integration) of the structure in the subgroup of students with a high level of the general indicator of self-organization of activity is 3 times higher than in the subgroup of students with an average level of the general indicator of self-organization of activity. It can be argued that in the subgroup of students with a high level of the general indicator of self-organization of activity, the integrative mechanisms of the structure of indicators of optimism, situational reflection, self-efficacy, reflection of communication and interaction with others, purposefulness, persistence, intolerance to uncertainty are more pronounced.

The degree of divergence of the structure of personal resources of coping behavior is 1,5 times higher in students with an average level of the general indicator of selforganization of activity, which indicates the differentiating nature of the links between the measured indicators.

On the basis of the presented structureograms, the basic components were established in the structure of the measured indicators in a subgroup of students with an average and high level of the general indicator of self-organization of activity. The results are shown in Table 2 .

Table 2. Weighted values of indicators of personal resources of coping behavior in students with different levels of the general indicator of self-organization of activity

\begin{tabular}{|c|c|c|c|c|c|c|}
\hline \multirow{2}{*}{ Indicators } & \multicolumn{5}{|c|}{ Middle level } & \multicolumn{3}{c|}{ High level } \\
\cline { 2 - 7 } & \multicolumn{5}{|c|}{ Component structural weight (W) } \\
\cline { 2 - 7 } & + & - & $\Sigma$ & + & - & $\Sigma$ \\
\hline Optimism & 0 & 0 & 0 & 23 & 5 & 28 \\
\hline Self-efficacy & 5 & 0 & 5 & 10 & 0 & 10 \\
\hline Self-control & 5 & 2 & 7 & 8 & 5 & 13 \\
\hline Retrospective reflection & 6 & 3 & 9 & 9 & 0 & 9 \\
\hline Situational reflection & 3 & 0 & 3 & 24 & 0 & 24 \\
\hline Perspective reflection & 5 & 2 & 7 & 8 & 0 & 8 \\
\hline Reflection of communication & 2 & 2 & 4 & 18 & 3 & 21 \\
\hline Reflexivity & 2 & 4 & 6 & 17 & 0 & 17 \\
\hline Planarity & 7 & 11 & 18 & 13 & 0 & 13 \\
\hline Purposefulness & 2 & 2 & 4 & 20 & 2 & 22 \\
\hline Persistence & 3 & 10 & 13 & 17 & 5 & 23 \\
\hline Fixation on structuring activities & 7 & 4 & 11 & 3 & 2 & 5 \\
\hline $\begin{array}{c}\text { Self-organization (through external } \\
\text { means) }\end{array}$ & 5 & 4 & 9 & 4 & 0 & 4 \\
\hline Orientation to the present & 2 & 2 & 4 & 2 & 14 & 16 \\
\hline $\begin{array}{c}\text { General indicator of self-organization } \\
\text { of activity }\end{array}$ & 7 & 4 & 11 & 16 & 0 & 16 \\
\hline Tolerance of uncertainty & 5 & 5 & 10 & 0 & 2 & 2 \\
\hline
\end{tabular}




\begin{tabular}{|c|c|c|c|c|c|c|}
\hline Uncertainty tolerance & 4 & 2 & 6 & 22 & 0 & 22 \\
\hline $\begin{array}{c}\text { Interpersonal intolerance to } \\
\text { uncertainty }\end{array}$ & 2 & 5 & 7 & 7 & 2 & 9 \\
\hline
\end{tabular}

As can be seen from Table 2, the basic components that ensure the structural integration of the system of personal properties in the subgroup of students with a high level of general indicator of self-organization of activity are: optimism $(\mathrm{W}=28)$; situational reflection $(\mathrm{W}=$ $24)$; persistence (23); purposefulness $(\mathrm{W}=22)$; intolerance to uncertainty $(\mathrm{W}=22)$.

At the final stage of the implementation of the method of structural-psychological analysis, a qualitative analysis was carried out, matrices and structuralograms were compared for their «homogeneity-heterogeneity». For these purposes, the express- $\mathrm{x}^{2}$ method was used. The results are shown in Table 3.

Table 3. Comparison of intercorrelation matrices of indicators of personal resources of coping

behavior in students with different levels of the general indicator of self-organization of activity according to the express criterion- $\mathrm{x}^{2}$

\begin{tabular}{|c|c|c|}
\hline & Middle level & High level \\
\hline Middle level & 1,000 & \\
\hline High level & $\mathrm{r}=-0,536$ & 1,000 \\
& $\mathrm{p}=0,022$ & \\
\hline
\end{tabular}

The structures of the components of personal properties in the subgroup of students with an average level of the general indicator of self-organization of activity and in the subgroup of students with a high level of the general indicator of self-organization of activity differ qualitatively (and not only in the degree of their organization) from each other in the content of relationships within them, therefore, they are heterogeneous.

\section{Discussion}

Analysis of the structuralogram of coping behavior personal resources for a subgroup of students with an average level of the general indicator of self-organization of activity showed that the optimism indicator is not associated with the coping behavior personal resources (Picture 1). In the subgroup of students with a high level of general indicator of self-organization of activity (Picture 2), the indicator of optimism positively correlates with such indicators as self-efficacy $(r=0,671, p=0,000)$, self-control $(r=0,619, p=0,000)$, retrospective reflection $(\mathrm{r}=0, .474, \mathrm{p}=0,005)$, situational reflection $(\mathrm{r}=0,364, \mathrm{p}=0,034)$, communication reflection $(\mathrm{r}=0,418, \mathrm{p}=0,014)$, reflexivity $(\mathrm{r}=0,443, \mathrm{p}=0,009)$, orderliness $(r=0,360, p=0,036)$, purposefulness $(r=0,528, p=0,001)$, persistence $(r=$ $0,385, p=0,024)$ and negatively correlates with the indicator of orientation to the present ( $\mathrm{r}$ $=-0,533, p=0,001)$ and interpersonal intolerance to uncertainty $(r=-0,364, p=0,034)$. The more expressed the positive expectations of the future in students, the more they are inclined to analyze and evaluate the past and themselves in it, what is happening, a subjective feeling of personal effectiveness, the desire to control their behavior and emotions, tactical daily planning, and the achievement of goals.

The indicator of subjective feeling of personal effectiveness, in the subgroup of students with a high level of the general indicator of self-organization of activity, is positively associated with purposefulness $(\mathrm{r}=0,416, \mathrm{p}=0,014)$ and perseverance $(\mathrm{r}=0,391, \mathrm{p}=$ $0,022)$, the indicator of self-organization of activity, the indicator of self-efficacy is positively associated with the indicator of tolerance to uncertainty $(r=0,492, p=0,004)$.

It is very interesting that the indicators of orderliness, purposefulness and perseverance in a subgroup of students with a high level of the general indicator of self-organization of 
activity are positively associated with situational reflection, reflection of communication, reflexivity. In the subgroup of students with an average level of the general indicator of self-organization of activity, negative links were found between the indicator of planning with retrospective reflection, reflexivity. Consequently, comprehension and analysis of the current situation is necessary for the implementation of tactical planning, setting and achieving (taking into account changes in the elements of a specific situation) the set goal.

In our study, it was found that the indicator of self-control in the subgroup of students with a high level of the general indicator of self-organization of activity is positively associated with purposefulness, and in the subgroup of students with an average level of the general indicator of self-organization of activity, the indicator of self-control is positively associated with persistence. The results of our study showed the peculiarities of the relationship between self-control and strategic goal-setting and persistence, depending on the level of the general indicator of self-organization of activity. Somewhat different results were established by S.A. Litvinova in the study of self-organization of students' activities. The author has established the following pattern: the more strongly expressed in a person's own I are such qualities and resources as «Life energy», «Self-control», «Perseverance» and «Courage», the more he demonstrates «determination» and «persistence in achieving goals», as well as a high level of self-organization towards activities in general [21].

In the framework of the study, it was found that the highest index of the general organization of the structure of the measured indicators is observed in the subgroup of students with a high level of the general indicator of self-organization of activity. It should be noted that the index of general organization of the structure of personal resources of coping behavior among students with a high level of the general indicator of selforganization of activity is 13 times higher than in the subgroup of students with an average level of the general indicator of self-organization of activity. It can be argued that in the subgroup of students with a high level of the general indicator of self-organization of activity, the personal resources of coping behavior represent an integral structure of personality traits that contribute to effective coping with many difficult situations. Consequently, structuring personal time, tactical planning and strategic goal-setting contribute to the transformation of stressful situations or adaptation to them. Results close to our research were found in the work of M. Pakhmutova [14]. The author found that such characteristics of activities as flexibility (correction), purposefulness (goal-setting), planning and self-control are most deeply integrated into the structure of personal qualities. Personal characteristics are manifested in activities, forming stable combinations and the most pronounced are such traits as risk avoidance, sociability and self-control of behavior. In addition, the researchers found that when planning activities, subjects are guided by relationships with their closest environment (in our study, this corresponds to communicative reflection), while in the self-control of activities they rely on high demands and their own discretion, i.e. reflexivity. Our data on the relationship between planning and reflexivity, self-control and reflexivity coincide with the results of the study by $M$. Pakhmutova [14].

The results of the study showed that the basic components that ensure the structural integration of the system of personal properties in a subgroup of students with a high level of general indicator of self-organization of activity are: optimism; situational reflection; persistence; purposefulness; intolerance to uncertainty. Consequently, in a stressful situation in a subgroup of students with a high level of the general indicator of selforganization of activity, the following mechanisms are triggered: students strive to analyze current events, assessing a stressful situation and available opportunities to overcome it, hope for the best development of events, set specific goals, purposefully and persistently strive to achieve their goals. In foreign studies devoted to the study of adolescence, motivation, goal-setting and planning of the life path are actively studied. A feature of 
adolescence is life path planning. Thus, researchers G. Oettingen, YJ. Pak, K. Schnetter, studying the relationship between thinking about the future and activity to achieve the goal, that strong commitment to a goal arises in the light of favorable expectations, and weak commitment to a goal arises in the light of unfavorable expectations [22]. Alexander K. Koch and Julia Nafziger in their study showed the strength and limits of self-regulation through goals. They point out that goals increase a person's motivation, but only to a certain point and are often painful means of self-discipline. The authors conclude that larger selfcontrol problems can lead to tougher goals, but for serious true bias, goals are either devoid of motivating power or too painful to be accepted [23]. Based on the structural analysis, we found that students are trying to determine the likelihood of an event (identified the relationship of intolerance to uncertainty with all types of reflection) and strive for clarity and orderliness, making volitional efforts to complete the work begun (relationships of intolerance to uncertainty with persistence and purposefulness are established).

As follows from the presented results, in the subgroup of students with an average level of the general indicator of self-organization of activity, there are no basic components that would ensure the structural integration of the system.

\section{Conclusions}

The results of the study of the features of the structural organization of personal resources of coping behavior of students with different levels of self-organization of activity allowed us to draw the following conclusions

In the subgroup of students with a high level of the general indicator of selforganization of activity, the integrative mechanisms of the structure of indicators of optimism, situational reflection, self-efficacy, reflection of communication and interaction with others, determination, persistence, intolerance to uncertainty are more pronounced. The differentiating nature of connections between the personal resources of coping behavior in students with an average level of the general indicator of self-organization of activity has been established. It can be argued that in the subgroup of students with a high level of the general indicator of self-organization of activity, the personal resources of coping behavior represent an integral structure of personality traits that contribute to effective coping with many difficult situations.

The basic components that ensure the structural integration of the system of personal properties in the subgroup of students with a high level of the general indicator of selforganization of activity are: optimism; situational reflection; persistence; purposefulness; intolerance to uncertainty. While in the subgroup of students with an average level of the general indicator of self-organization of activity, there are no basic components that would ensure the structural integration of the system. The structures of the components of personal properties in the subgroup of students with an average level of the general indicator of selforganization of activity and in the subgroup of students with a high level of the general indicator of self-organization of activity are heterogeneous.

Research prospects are aimed at studying the structure of personal resources of coping behavior of students with a low level of the general indicator of self-organization of activity and the development of a training program for the development of personal resources of coping behavior by means of increasing the degree of self-organization of students' activities.

\section{References}


1. T. V. Eksakusto, I. A. Kibal'chenko Systems psychology and sociology, 2, 45-58(2020 DOI: $10.25688 / 2223-6872.2020 .34 .2 .04$

2. G. Nikolaevna, Travinova Mir nauki, kultury, obrazovaniya, 1, 89-91 (2020) DOI: 10.24411/1991-5497-2020-00037

3. S. A. Khazova, N. S. Shipova, T. N. Adeeva, I. V. Tikhonova, Counseling psychology and psychotherapy, 4, 101-118 (2018) https://www.elibrary.ru/item.asp?id=36574439

4. S. N. Kostromina Professional and personal development of a future specialist, St. Petersburg, St. Petersburg State University, 25-27. (2012) https://www.elibrary.ru/item.asp?id=36524143

5. N. F. Efremova, Russian psychological journal, 2, 227-244 (2017) DOI: 10.21702/rpj.2017.2.13

6. E. Suroedova, Y. Tushnova, E. Belousova, E3S Web of Conferences, 175, 15028 (2020) DOI https://doi.org/10.1051/e3sconf/202017515028

7. N. N. Mozgovaya, E. A. Suroedova, International Journal of Cognitive Research in Science, Engineering and Education, 2, 71-77 (2013) https://elibrary.ru/item.asp?id=24330956 (Last accessed 12.08.2020)

8. I. V. Abakumova, N. N. Mironenkova, D. V. Pen'kov, Russian psychological journal, 2, 63-80 (2019) DOI: 10.21702/rpj.2019.2.4

9. O. Nikolenko, L. Zheldochenko, N. Lomova, 175, 15029 (2020) DOI: https://doi.org/10.1051/e3sconf/202017515029

10. A. K. Belousova, E. E. Belousova, International Journal of Psychology, S1, 540 (2016) https://elibrary.ru/item.asp?id=27358330 (Last accessed 12.08.2020)

11. S. A. Khazova, N. S. Shipova, T. N. Adeeva, I. V. Tikhonova, Counseling psychology and psychotherapy, 4, 101-118 (2018) DOI: 10.17759/cpp.2018260407

12. M. Pakhmutova, A. Khinkanina, 4th international multidisciplinary scientific conference on social sciences and arts sgem 2017, conference proceedings, 765-770 (2017) DOI: 10.5593/sgemsocial2017/34/S13.098

13. Y. A. Zubok, V. I. Chuprov, A. S. Lyubutov, Vestnik Tomskogo gosudarstvennogo universiteta, 53, 59-75 (2020) DOI: 10.17223/1998863X/53/7

14. M. Paatova, M. Pakhmutova, The european proceedings of social \& behavioural sciences epsbs, 1466-1473 (2018) DOI: 10.15405/epsbs.2019.03.02.170

15. A. A. Bondaletov, Sotsiologicheskie issledovaniya, 3, $132 \quad$ (2015) https://apps.webofknowledge.com/full_record.do?product=WOS\&search_mode $=$ Gener

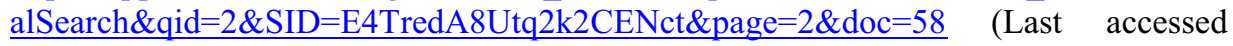
14.08.2020)

16. K. Friston, Frontiers in psychology, 9, 579 (2018) DOI: 10.3389/fpsyg.2018.00579

17. J. Nederhand, E.-H. Klijn, M. van der Steen, M. van Twist, Policy Sciences, 52, 233253 (2019) https://doi.org/10.1007/s11077-018-9342-4

18. C. Moulin-Frier, S. M. Nguyen, P.-Y. Oudeyer, Frontiers in psychology, 4, 1006 (2014) DOI: 10.3389/fpsyg.2013.01006

19. R. Dale, R. Fusaroli, N. D. Duran, D. C. Richardson, Psychology of Learning and Motivation, 59, 43-95 (2013) DOI: 10.1016/B978-0-12-407187-2.00002-2

20. T. O. Gordeeva, O. A. Sychev, E. N. Osin Psychological diagnostics, 2, 36-64 (2010) https://www.elibrary.ru/item.asp? $\mathrm{id}=22310248$ (Last accessed 12.08.2020)

21. S. A. Litvina, Siberian Journal of Psychology, 61, 33-46 (2016) DOI: $10.17223 / 17267080 / 61 / 3$ 
22. G. Oettingen, Y. J. Pak, K. Schnetter, Journal of personality and social psychology, 5, 736-753 (201) DOI: 10.1037//0022-3514.80.5.736

23. A. K. Koch, J. Nafziger, Scandinavian journal of economics, 1, 212-227, DOI: 10.1111/j.1467-9442.2010.01641.X 